(RESEARCH ARTICLE)

\title{
Development and characterization of self micro emulsifying drug delivery system of rosavastatin
}

\author{
Mounika P* , Vishnu P, Konde Abbulu \\ Department of Pharmaceutics, CMR College of pharmacy, Medchal, Hyderabad, Telangana, India.
}

Publication history: Received on 10 December 2017; revised on 11 February 2018; accepted on 24 February 2018

https://doi.org/10.30574/gscbps.2018.3.1.0060

\begin{abstract}
The present study was undertaken to enhance solubility and dissolution rate of rosuvastatin by formulating it as a self -micro emulsifying drug delivery system (SMEDDS). The SMEDDS were prepared by using castor oil and sesame oil as oils, Tween 80 as surfactant and PEG 200 as co-surfactant. The prepared SMEDDS were further evaluated for drug content, thermodynamic stability and in vitro drug release. Among all the formulations the drug release for F2 formulation was $99.70 \%$ in 120 min. So it was considered as the optimized formulation. The selected optimized F2 formulation was characterized by drug excipient compatibility using FTIR spectroscopy, scanning electron microscopy and globule size. The stability studies indicate that the formulated SMEDDS was stable for 60 days.
\end{abstract}

Keywords: Rosuvastatin; FTIR; SMEDDS; Tween80; PEG- 200; Ternary phase diagram; Globule size analysis

\section{Introduction}

In recent years, the formulation of poorly aqueous soluble drugs is a challenging job to scientist. Oral delivery of poorly aqueous soluble drugs is frequently associated with low bioavailability, high inter and intra-subject variability lack of dose proportionality. These class of Biopharmaceutical classification (BCS-II) II drugs. Here drug dissolution is the rate limiting step is the absorption process. To overcome this problem, different formulation approaches have been exploited including the use of surfactant, lipids, permeation enhancers and formation of salt, solid dispersion and colloidal vesicles like liposome. The most popular and commercially viable lipid based formulation approach for solving this problem is self-micro-emulsifying drug delivery system (SMEDDS) [1].

In modern drug discovery, various techniques are used to improve the bioavailability of those drugs like salt formation, $\mathrm{pH}$ change, $\beta$-cyclodextrines complex, micro-emulsion etc. Self-micro-emulsifying drug delivery (SMEDDS) is one of the methods for the improvement of oral bioavailability. SMEDDS are a class of emulsion that has received particular attention as a means of enhancing oral bioavailability of poorly absorbed drugs. These systems are essentially mixes of oil and surfactant (sometimes with added co-surfactant) that form emulsion on mixing with water with little or no energy input [2].

The main objective of the investigation is to formulate, optimize and stabilize SMEDDS containing rosavastatin with surfactants and co-surfactants. Rosavastatin is poorly soluble drug, SMEDDS are prepared to increase their solubility in gastric fluid and improve bioavailability.

\footnotetext{
${ }^{*}$ Corresponding author

E-mail address: pamparimounika@ gmail.com
}

Copyright (C) 2018 Author(s) retain the copyright of this article. This article is published under the terms of the Creative Commons Attribution Liscense 4.0. 


\section{Material and methods}

\subsection{Materials}

\subsubsection{Chemicals}

Rosuvastatin was gifted from Sun pharmaceutical Ltd, Mumbai, Castor oil (Color cone Asia Ltd., Verna, Goa), Sesame oil (MJ Biopharmaceuticals, Mumbai), PEG-200(MJ Biopharmaceuticals, Mumbai), Tween 80(MJ Biopharmaceuticals, Mumbai).

\subsubsection{Instruments Used}

UV-Visible Spectrophotometer obtained from (PG Instruments, T60), Weighing Balance (XB120A) (Essae-Teraoka ltd, DS-852j), Over Head Stirrer (Techno Scientific products, Bangalore), Over Head Stirrer (Techno Scientific products, Bangalore), Rheometer (DV-E) (Brooke Field Viscometer), Magnetic Stirrer (MB instruments, MB575, Delhi), Mechanical Stirrer (MB instruments, MB575, Delhi), Dissolution apparatus (DS 8000 Lab, India).

\subsection{Methods}

\subsubsection{Solubility studies}

Solubility of rosuvastatin was determined in various modified oils, surfactants, and co-surfactants. Two mL of each component was taken in screw cap vials with known quantity of excess drug. A vortex mixer (Spinix, India) was used to facilitate the solubilization. Sealed vials were kept on isothermal mechanical shaker at $40 \pm 2{ }^{\circ} \mathrm{C}$ for 72 hours. After equilibrium, each test tube was centrifuged at $6000 \mathrm{rpm}$ for $20 \mathrm{~min}$ using a centrifuge (R-8C, Remi, India). The supernatant was filtered through membrane filter using $0.45 \mu \mathrm{m}$ filter disk. The filtered solution was appropriately diluted with methanol, and UV absorbance was measured at $243 \mathrm{~nm}$ [10].

\subsubsection{UV spectroscopy}

The $10 \mathrm{mg}$ of rosuvastatin was dissolved in $10 \mathrm{~mL}$ of $0.1 \mathrm{~N} \mathrm{HCl}$ by slight shaking to get the concentration of $(1000$ $\mu \mathrm{g} / \mathrm{mL}) .1 \mathrm{~mL}$ of this solution was taken and made up to $10 \mathrm{~mL}$ with $0.1 \mathrm{~N} \mathrm{HCl}$ which gives $100 \mu \mathrm{g} / \mathrm{mL}$ concentration (stock solution). From the stock solution take $2.5 \mathrm{~mL}$ of the solution and make up to the mark with $0.1 \mathrm{~N} \mathrm{HCl}$ to get the concentration of $25 \mu \mathrm{g} / \mathrm{mL}$, this solution was analyzed in UV spectrophotometer of (model No. T60), in order to determine the absorption maxima.

For construction of calibration curve using $0.1 \mathrm{~N} \mathrm{HCl}$ buffer, $10 \mathrm{mg}$ of Rosuvastatin was dissolved in $10 \mathrm{~mL}$ of $0.1 \mathrm{~N} \mathrm{HCl}$ by slight shaking $(1000 \mu \mathrm{g} / \mathrm{mL}) .1 \mathrm{~mL}$ of this solution was taken and made up to $10 \mathrm{ml}$ with $0.1 \mathrm{~N} \mathrm{HCl}$, which gives 100 $\mu \mathrm{g} / \mathrm{mL}$ concentration (stock solution). From the stock solution, concentrations of $5,10,15,20,25 \mathrm{and} 30 \mu \mathrm{g} / \mathrm{mL} \mathrm{in}$ $0.1 \mathrm{~N} \mathrm{HCl}$ were prepared. The absorbance of diluted solutions was measured at $292 \mathrm{~nm}$ and a standard plot was drawn using the data obtained. The correlation coefficient was calculated [4].

\subsubsection{Emulsification studies}

Emulsification studies were conducted to select the best surfactant and co-solvent from a range of co-solvents and surfactants that are used for oral drug delivery. The surfactant and co-solvent were mixed at a fixed ratio of 2:1. The oil to S-Co mixture ratio was $1: 3$, and the mixture was homogenized with the aid of gentle heat $\left(30-40{ }^{\circ} \mathrm{C}\right)$ and vortexed for $2 \mathrm{~min}$ in a vortex mixer. $0.2 \mathrm{~mL}$ of the mixture was diluted with $200 \mathrm{~mL}$ of distilled water with gentle stirring on a magnetic stirrer. The ease of formation of emulsions was noted by noting the time required to give uniform emulsion. The resulting emulsions were observed visually for the relative turbidity [11].

\subsubsection{Construction of pseudo ternary phase diagrams}

Pseudo ternary phase diagrams were constructed using the water titration method. The surfactant and co-surfactant were mixed in different volume ratios (1:1, 2:1 and 3:1). Oil and S-mixture (S/Co-S) were mixed thoroughly in different volume ratios $(9: 1,8: 2,7: 3,6: 4,5: 5,4: 6,3: 7,2: 8$ and 1:9) in different test tubes. The mixture in each tube was mixed homogeneously using a vortex mixer until the oily liquid mixture was obtained at room temperature. Water was then added drop-by-drop at $0.05-\mathrm{mL}$ increments using a pipette into each oily mixture. During the titration, samples were stirred vigorously for a sufficient length of time for homogenization and visually monitored against a dark background by illuminating the samples with white light. The concentrations of water at which the solutions became clear were noted down. A pseudo ternary phase diagram was prepared using Triplot free version [12- 13]. 


\subsubsection{Preparation of SMEDDS}

Rosuvastatin was added in the accurately weighed amount of oil into a screw-capped glass vial and heated in a water bath at $40^{\circ} \mathrm{C}$. The surfactant and co-surfactant were added to the oily mix using positive displacement pipette and stirred with magnetic bar. The formulation was further sonicated (Ultrasonic Cleaner EN-30-US, Electroquip, India) for 15 min and stored at room temperature until its use in subsequent studies. Six SMEDDS formulations were prepared, and their self-emulsifying performance was compared. The composition of six formulations is shown in Table 1.

Table 1 Formulation of Rosuvastatin SMEDDS [14]

\begin{tabular}{lllllll}
\hline Ingredients & F1 & F2 & F3 & F4 & F5 & F6 \\
\hline Rosuvastatin(mg) & 50 & 50 & 50 & 50 & 50 & 50 \\
Castor oil(ml) & 45 & 45 & 45 & - & - & - \\
Sesame oil(ml) & - & - & - & 45 & 45 & 45 \\
Tween 80(ml) & 175 & 125 & 75 & 175 & 125 & 75 \\
PEG 200(ml) & 75 & 125 & 175 & 75 & 125 & 175 \\
\hline
\end{tabular}

\subsubsection{Drug content}

The total amount of the drug in the formulation was analyzed by dissolving the formulation in $10 \mathrm{~mL}$ ACN. This solution was vortexed for $10 \mathrm{~min}$ in a vortex mixture. The mixture was centrifuged at $5000 \mathrm{rpm}$ for $5 \mathrm{~min}$. Then, the supernatant was filtered through a Whatman filter paper. The filtrate was analyzed by UV after suitable dilution at $292 \mathrm{~nm}$ [15].

\subsubsection{Thermodynamic stability studies}

The objective of the thermodynamic stability was to evaluate the effect of temperature variation on the SMEDDS formulations. Rosuvastatin SMEDDS were centrifuged at 15,000 rpm for $15 \mathrm{~min}$ and the formulations were observed visually for phase separation. The formulations were subjected to freeze-thaw cycles $\left(-5^{\circ} \mathrm{C}\right.$ for 2 days followed by $+40^{\circ} \mathrm{C}$ for 2 days). The samples were observed visually after the freeze-thaw cycles. Thermodynamically stable formulations were selected for further characterization [5].

\subsubsection{Cloud point measurement}

The formulations were compared for cloud point value. Each formulation was diluted with water in the ratio of 1:100 and placed in a water bath with a gradual increase in temperature. At the cloud point, drop in sample $\%$ transmittance was measured spectrophotometrically [6].

\subsubsection{In vitro dissolution}

Rosuvastatin SMEDDS was filled in a capsule shell and the in vitro release profile was taken in a USP apparatus I at 37 $\pm 0.5^{\circ} \mathrm{C}$, at $100 \mathrm{rpm}$, in $0.1 \mathrm{~N} \mathrm{HCl}$. At predetermined intervals, $5 \mathrm{~mL}$ of the medium was sampled and filtered through a Whatman filter paper. The resulting solution $(1 \mathrm{~mL})$ was mixed with $1 \mathrm{~mL}$ of acetonitrile, vortexed for 2 min and centrifuged at 10,000 rpm for $10 \mathrm{~min}$. Then, $2 \mathrm{ml}$ of the supernatant layer was analyzed by UV spectrophotometer at 243 $\mathrm{nm}[15]$.

\subsubsection{Characterization of SMEDDS}

Drug -excipient compatibility study using FTIR spectroscopy

The physical compatibility between the pure drug and e used in the research was tested by Infra-Red (IR) spectroscopy. FTIR absorption spectra of pure drug and physical mixture were recorded in the range of $400-4000 \mathrm{~cm}-1 \mathrm{by} \mathrm{KBr}$ disc method using FTIR spectrophotometer.

Scanning electron microscopy (SEM)

The samples were mounted on a specimen studies using double sided adhesive tape, and gold-palladium alloy of $120 \AA$ Kness was coated on the sample using spatter coating unit (Model E5100 Polaron, UK) in an argon ambient of 8-10 pascal with plasma voltage about $2 \mathrm{Kv}$ and discharge current about $20 \mathrm{~mA}$. The sputtering was done for nearly 3 minutes to obtain uniform coating on the samples to enable good quality SEM images. The SEM operated at the low accelerating 
voltage of about $15 \mathrm{Kv}$ with the load current of about $80 \mathrm{~mA}$. The condenser lens position was maintained between 4.4 - 5.1. The objective lens aperture has a diameter of 240 microns and the working distance WD $=39 \mathrm{~mm}$.

Globule size analysis

The globule size, size distribution and zeta potential were analyzed by dynamic light scattering with a globule size apparatus (Malvern Zeta sizer version 6.11, United Kingdom). Liquid SMEDDS were diluted 250-times with 0.1 N HCL at $25{ }^{\circ} \mathrm{C}$ under gentle shaking. After equilibrium, the emulsions were filtered through a Whatman filter paper. The filtrates were analyzed by Zeta sizer [16].

\subsubsection{Determination of the stability of the optimized formulation}

Accelerated stability studies were also performed for determination of the shelf-life of the optimized formulations. The SMEDDS formulations were kept at three different temperatures and ambient humidity conditions $(30 \pm 0.5,40 \pm 0.5$ and $50 \pm 0.5^{\circ} \mathrm{C}$ ) for 2 months. The samples were withdrawn at specified time intervals $(0,30$, and 60 days) [18-19].

\section{Results and discussion}

\subsection{Solubility}

The results of solubility studies showed that, 0.1 N HCL solutions has more solubility when compared to water and 6.8 pH buffer solutions.

Table 2 Solubility studies of rosuvastatin

\begin{tabular}{lll}
\hline Sr. No. & Medium & Solubility $(\mathrm{mg} / \mathbf{m l})$ \\
\hline 1 & Water & $0.046 \pm 0.08$ \\
2 & $0.1 \mathrm{~N} \mathrm{HCl}$ & $0.225 \pm 0.29$ \\
3 & $6.8 \mathrm{pH}$ buffer & $0.174 \pm 0.12$ \\
\hline
\end{tabular}

Table 3 Emulsification studies

\begin{tabular}{lllll}
\hline Oil & Surfactant & Co-surfactant & D.T. & \%T \\
\hline Castor oil & Tween 80(40:60) & PEG 200 & $20-45$ & 71.09 \\
Castor oil & Tween 80(30:70) & PEG 200 & $20-45$ & 75.11 \\
Castor oil & Tween 80(20:80) & PEG 200 & $0-20$ & 87.50 \\
Castor oil & Tween 80(10:90) & PEG 200 & $0-20$ & 93.16 \\
Sesame oil & Tween 80(40:60) & PEG 200 & $20-45$ & 68.60 \\
Sesame oil & Tween 80(30:70) & PEG 200 & $20-45$ & 70.71 \\
Sesame oil & Tween 80(20:80) & PEG 200 & $0-20$ & 82.09 \\
Sesame oil & Tween 80(10:90) & PEG 200 & $0-20$ & 91.10 \\
\hline
\end{tabular}




\subsection{UV Spectroscopy}

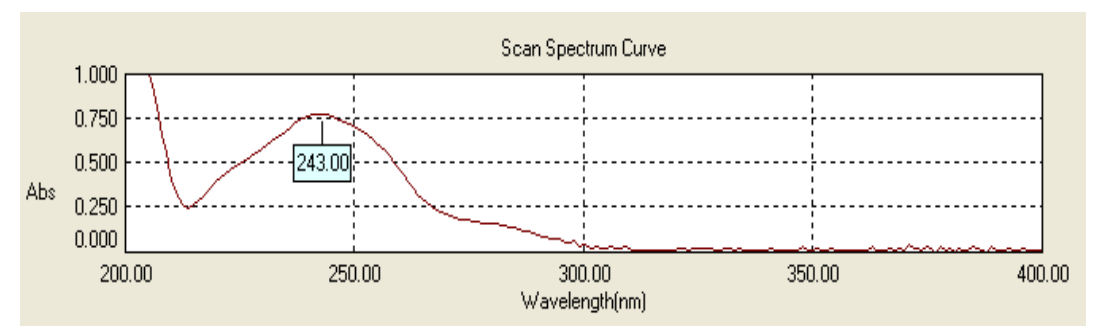

Figure $1 \mathrm{UV}$ spectrum of rosuvastatin in $0.1 \mathrm{~N} \mathrm{HCl}$ buffer

The absorption maxima of rosuvasatin $(\lambda$-max) in $0.1 \mathrm{~N} \mathrm{HCl}$ buffer is $243 \mathrm{~nm}$.

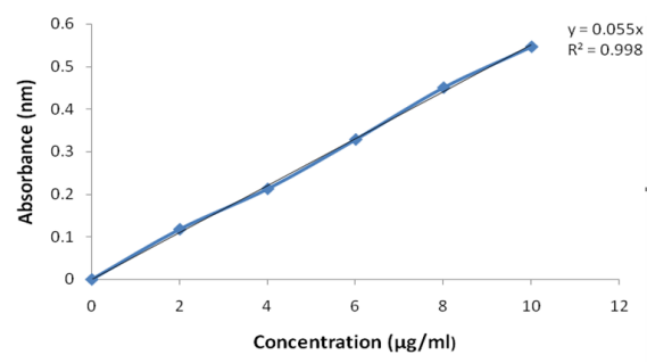

Figure 2 Calibration curve in $0.1 \mathrm{~N} \mathrm{HCl}$ Buffer

The linearity was found to be in the range of $2-10 \mu \mathrm{g} / \mathrm{ml}$ in $0.1 \mathrm{~N}$ HCL buffer and the method obeys Beer-lambert's law.

\subsection{Construction of ternary phase diagram}

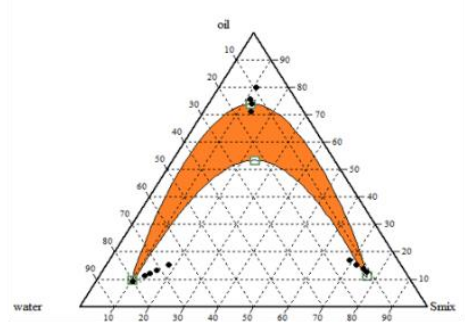

A

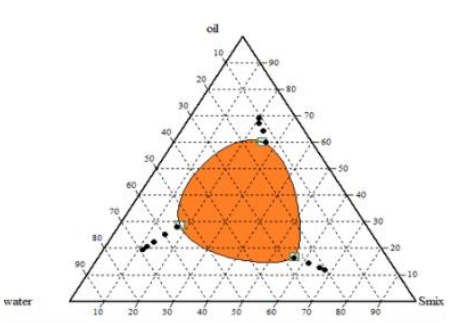

D

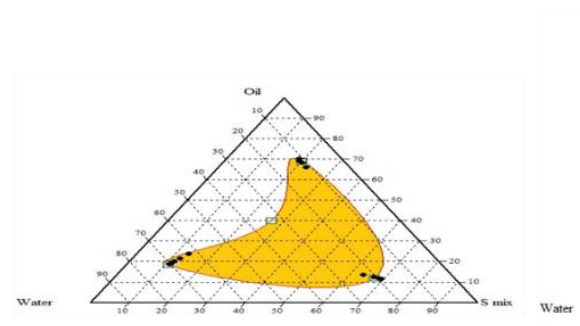

B

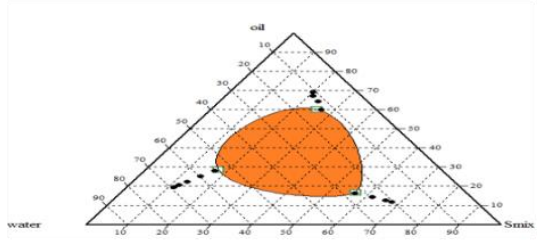

E
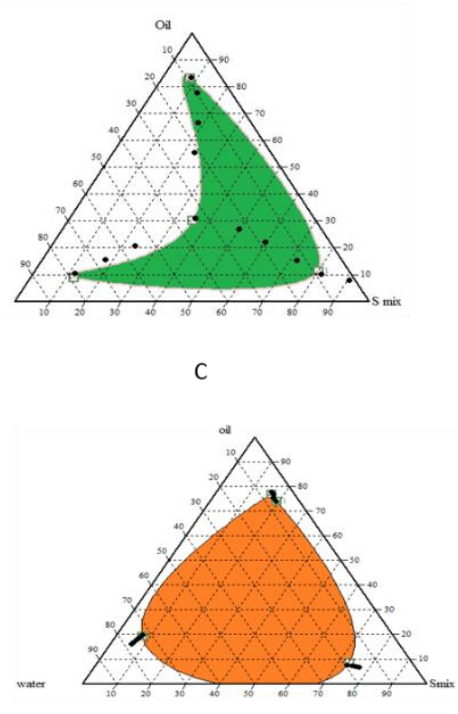

$\mathrm{F}$

Figure 3 Pseudoternary phase diagrams of oil, $S_{\text {mix }}$ and water

Ratio of (Oil: Surfactant) and $S_{\text {mix }}$ [A- 1:1(9:1-1:9), B-1:1(1:9-9:1), C-2:1(1:9-9:1), D-2:1(9:1-1:9), E- 3:1(1:9-9:1) and F$3: 1(9: 1-1: 9)]$.

The above mentioned figure $3 \mathrm{~F}$ in ternary phase diagram has got highest miscibility concentration compared to all other and found to be more stable concentration. 


\subsection{Drug content}

The drug content of the formulations was found to be $96.28-98.78 \%$.

Table 4 Drug content of SMEDDS formulations

\begin{tabular}{ll}
\hline Formulation code & Drug content \\
\hline F1 & $96.21 \pm 0.28$ \\
F2 & $98.78 \pm 0.38$ \\
F3 & $97.68 \pm 0.12$ \\
F4 & $96.92 \pm 0.34$ \\
F5 & $98.52 \pm 0.02$ \\
F6 & $97.92 \pm 0.18$ \\
\hline
\end{tabular}

The drug content of the formulations was found to be $96.28-98.78 \%$.

Table 5 Thermodynamic stability and cloud point of SMEDDS formulations

\begin{tabular}{llll}
\hline Formulation & Centrifugation test & Freeze thaw cycle & Cloud point $\left({ }^{\circ} \mathbf{c}\right)$ \\
\hline F1 & No Phase Separation & No Phase Separation & 71 \\
F2 & No Phase Separation & No Phase Separation & 65 \\
F3 & No Phase Separation & No Phase Separation & 69 \\
F4 & No Phase Separation & No Phase Separation & 65 \\
F5 & No Phase Separation & No Phase Separation & 76 \\
F6 & No Phase Separation & No Phase Separation & 98 \\
\hline
\end{tabular}

\subsection{In vitro drug release}

Among all the formulations the drug release for F2 formulation [rosuvastatin ( $5 \mathrm{mg}$ ), castor oil (45 ml), Tween 80 (125 $\mathrm{ml}$ ), PEG200 (125 ml)] the drug release was $99.70 \%$ in $120 \mathrm{~min}$. So it was considered as the optimized formulation.

Table 6 In vitro drug release of the formulated SMEDDS

\begin{tabular}{lllllll}
\hline Time (Min) & F1 & F2 & F3 & F4 & F5 & F6 \\
\hline 0 & 0 & 0 & 0 & 0 & 0 & 0 \\
5 & $83.87 \pm 0.12$ & $93.81 \pm 0.46$ & $75.11 \pm 0.24$ & $79.18 \pm 0.12$ & $89.98 \pm 0.02$ & $71.15 \pm 0.32$ \\
10 & $85.51 \pm 0.36$ & $94.50 \pm 0.54$ & $78.80 \pm 0.18$ & $82.21 \pm 0.26$ & $91.56 \pm 0.24$ & $77.89 \pm 0.41$ \\
20 & $97.70 \pm 0.22$ & $95.08 \pm 0.12$ & $82.16 \pm 0.06$ & $85.53 \pm 0.12$ & $92.23 \pm 0.16$ & $80.13 \pm 0.22$ \\
30 & $88.16 \pm 0.18$ & $95.72 \pm 0.36$ & $85.53 \pm 0.01$ & $87.06 \pm 0.34$ & $93.31 \pm 0.28$ & $82.25 \pm 0.16$ \\
45 & $90.02 \pm 0.06$ & $96.11 \pm 0.22$ & $87.70 \pm 0.12$ & $88.11 \pm 0.58$ & $93.89 \pm 0.42$ & $85.57 \pm 0.01$ \\
60 & $91.13 \pm 0.18$ & $97.32 \pm 0.16$ & $90.16 \pm 0.36$ & $90.57 \pm 0.02$ & $94.47 \pm 0.18$ & $87.77 \pm 0.82$ \\
90 & $96.40 \pm 0.02$ & $98.16 \pm 0.24$ & $93.33 \pm 0.48$ & $93.37 \pm 0.16$ & $96.30 \pm 0.52$ & $88.80 \pm 0.16$ \\
120 & $98.71 \pm 0.24$ & $99.70 \pm 0.04$ & $95.58 \pm 0.08$ & $94.48 \pm 0.01$ & $96.88 \pm 0.36$ & $92.27 \pm 0.08$ \\
\hline
\end{tabular}

\subsection{Drug excipient compatibility}

Drug and excipients compatibility was confirmed by comparing spectra of FTIR analysis of pure drug with that of various excipients used in formulation. 


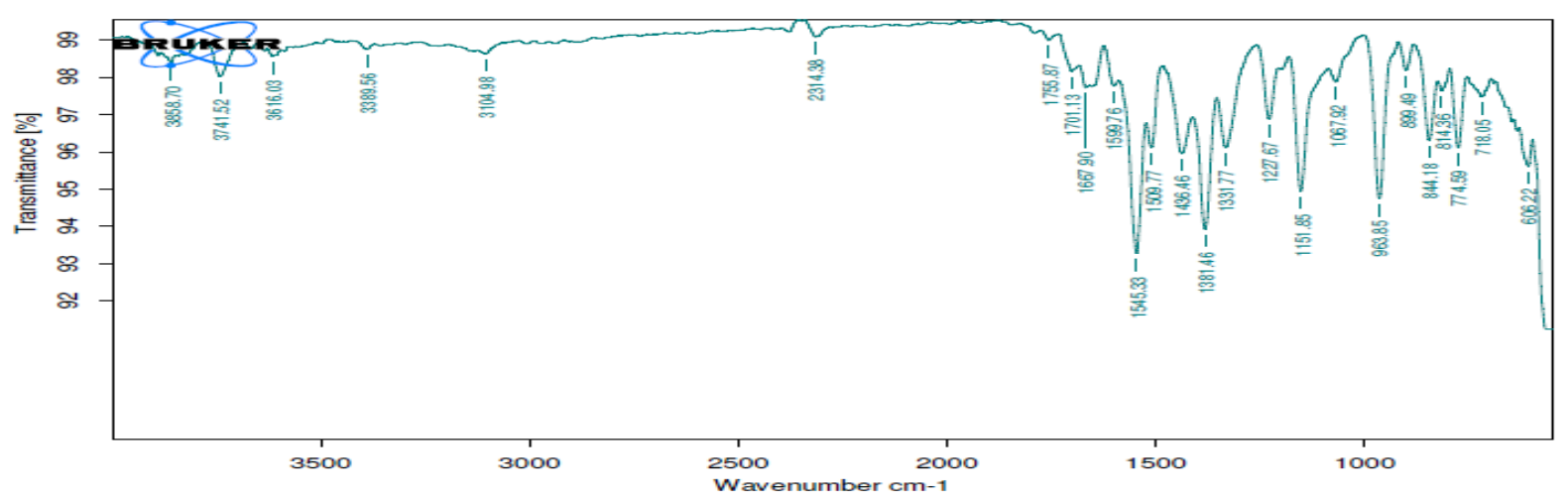

Figure 4 FTIR spectrum of pure rosuvastatin

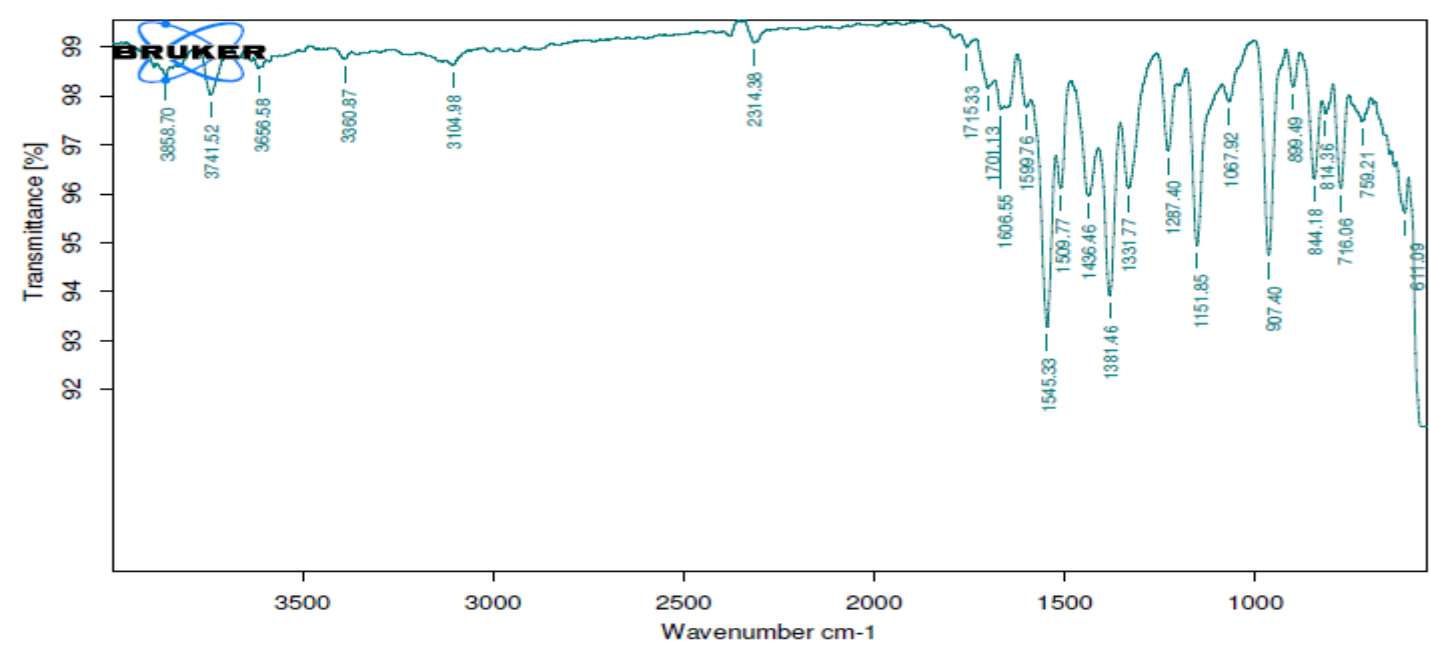

Figure 5 FTIR spectrum of rosuvastatin optimized formulation

FTIR Spectra of Rosuvastatin shows OH stretching at $3741.52 \mathrm{~cm}^{-1}, \mathrm{C}=0$ stretching at $1151.851381 .46 \mathrm{~cm}^{-1}$ shows s=o stretching. $907.41 \mathrm{~cm}^{-1}$ indicates $\mathrm{C}=\mathrm{C}$ bending, $716.05 \mathrm{~cm}^{-1}$ indicates $\mathrm{C}-\mathrm{H}$ bending. The FTIR Spectra of optimized formulation Shows OH stretching at $3741.52 \mathrm{~cm}^{-1}, \mathrm{C}=0$ stretching at $1151.851381 .46 \mathrm{~cm}^{-1}$ shows $\mathrm{S}=0$ stretching. 907.41 $\mathrm{cm}^{-1}$ indicates $\mathrm{C}=\mathrm{C}$ bending, $716.05 \mathrm{~cm}^{-1}$ Indicates $\mathrm{C}-\mathrm{H}$ bending.

Compatibility studies were performed using IR spectrophotometer. The IR spectrum of pure drug and physical mixture of drug and excipients were studied. The characteristic absorption peaks of were obtained as above and the drug is compatible with excipients.

\subsection{Scanning Electron Microscopy (SEM)}

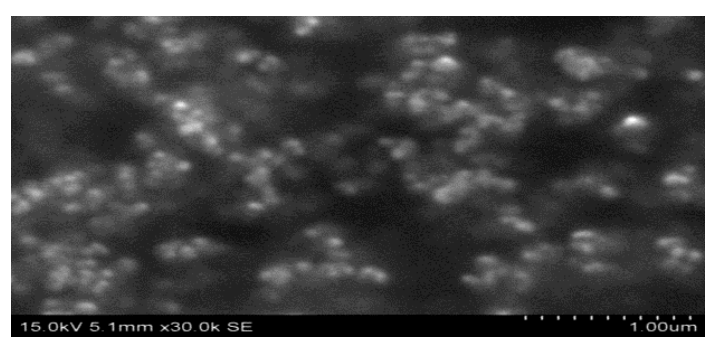

Figure 6 SEM globule size of optimized rosuvastatin formulation 
Table 7 Globule size analysis of the SMEDDS Formulation (F1-F6)

\begin{tabular}{ll}
\hline Formulation & Goluble size (nm) \\
\hline F1 & 121 \\
F2 & 116 \\
F3 & 118 \\
F4 & 126 \\
F5 & 122 \\
F6 & 124 \\
\hline
\end{tabular}

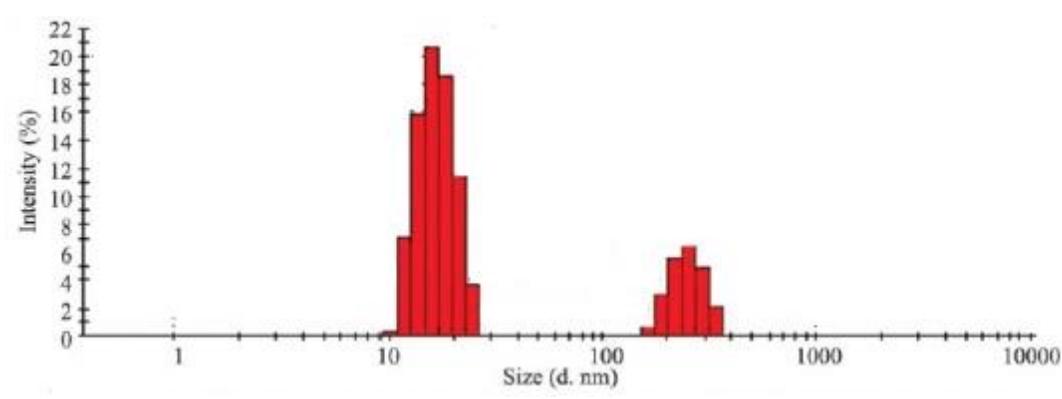

Figure 7 Globule size of optimized F2 formulation

\subsection{Stability Studies}

Table 8 In vitro drug release of the optimized formulation (F2)

\begin{tabular}{llll}
\hline Time (min) & \multicolumn{3}{l}{ Cumulative drug released (\% $\mathbf{S D})$} \\
\cline { 2 - 4 } & $\mathbf{1}^{\text {st }}$ day & $\mathbf{3 0}^{\text {th }}$ day & $\mathbf{6 0}^{\text {th }}$ day \\
\hline 0 & 0 & 0 & 0 \\
5 & $93.81 \pm 0.46$ & $92.96 \pm 0.52$ & $93.02 \pm 0.42$ \\
10 & $94.50 \pm 0.54$ & $93.51 \pm 0.65$ & $94.86 \pm 0.51$ \\
20 & $95.08 \pm 0.12$ & $94.26 \pm 0.18$ & $95.28 \pm 0.08$ \\
30 & $95.72 \pm 0.36$ & $94.89 \pm 0.42$ & $95.12 \pm 0.34$ \\
45 & $96.11 \pm 0.22$ & $95.82 \pm 0.29$ & $96.08 \pm 0.16$ \\
60 & $97.32 \pm 0.16$ & $96.28 \pm 0.20$ & $97.52 \pm 0.02$ \\
90 & $98.16 \pm 0.24$ & $97.92 \pm 0.27$ & $98.29 \pm 0.21$ \\
120 & $99.70 \pm 0.04$ & $98.86 \pm 0.06$ & $99.20 \pm 0.01$ \\
\hline
\end{tabular}

From the above conducted stability studies of optimized formulation for about 60 days by comparing the results we can say that there is no change in the optimized formula on storage which indicates that it passes the stability studies.

\section{Conclusion}

In the present study, SMEDDS of rosuvastatin were prepared by using oils, surfactants and co-surfactants like Castor oil, Sesame oil, PEG-200 and Tween 80. Among various six formulations (F1 to F6), F2 was found to be the best formulation with castor oil. The FTIR study of pure drug and physical mixture of drug and excipients revealed that there was no interaction between drug and polymers. The globule size of the SMEDDS formulations was found to be in the range of 113-128nm. The stability studies indicates the optimized formulation has stability for time period of $60 \mathrm{days}$. Further studies are also conducted for in vivo determination studies. 


\section{Compliance with ethical standards}

\section{Acknowledgments}

With deep gratitude, I would like to thank the Management, CMR College of Pharmacy for providing all the necessary equipment and facilities in the college campus to carry out inspiring research work.

\section{Disclosure of conflict of interest}

The authors have declared that no conflict of interest exists among them.

\section{References}

[1] Mittal P, Rana AC and Bala R. (2011). Lipid based self micro-emulsifying drug delivery system for lipophilic drugs - A review. International Research Journal of Pharmacy, 2(12), 75-80.

[2] Jawad A, Intan FS, Jiyauddin K, Asbi A, Budiasih S, Kalemullah M and Samer AD. (2014). Formulation and development of self micro-emulsifying drug delivery system (SMEDDS) of flurbiprofen. World Journal of Pharmaceutical Research, 3, 872-874.

[3] Aulton ME (2002). Pharmaceutics: The science of dosage form design. Churchill Livingstone, London, Second Edition.

[4] Patil P, Joshi P and Paradkar A. (2004). Effect of formulation variables on preparation and evaluation of gelled self-mulsifying drug delivery system (SEDDS) of ketoprofen. AAPS PharmSciTech, 5(3), 43-50.

[5] Kanga KB, Lee SJ, Chona KS, Jeong YS, Yuk HS and Khanga G. (2004). Development of self-micro emulsifying drug delivery systems for oral bioavailability enhancement of Simvastatin in Beagle Dogs. International Journal of Pharmaceutics, 274(1-2), 65-73.

[6] Subramanian N, Ray S, Ghosal S, Bhandra R and Moulik SP. (2004). Formulation design of self-micro emulsifying drug delivery systems for improved oral bioavailability of celecoxib. Biological and Pharmaceutical Bulletin, 27(12), 1993-1999.

[7] Land LM, Li P and Bummer PM. (2005). The influence of water content of triglyceride oils on the solubility of steroids. Pharmaceutical Research, 21(2), 254-260.

[8] Wei W, Yang W and Li Q. (2006). Enhanced bioavailability of silymarin by self-micro emulsifying drug delivery system. European Journal of Pharmaceutics and Biopharmaceutics, 63, 288-294.

[9] Manjula D, Venkata N, Sailaja G, Ramachandra M, Ranganath B. (2017). Formulation and characterization of cefixime microspheres. International Journal Pharmacy, 2017, 7(3), 138-146.

[10] Bora D, Borude P and Bhise K. (2012). Formulation and Evaluation of Self-micro emulsifying drug delivery system of low solubility drug for enhanced solubility and dissolution. Asian Journal of Biomedical and Pharmaceutical Sciences, 2(15), 7-14.

[11] Rane SS and Anderson BD. (2008). What determines drug solubility in lipid vehicles: Is it predictable?. Advanced Drug Delivery Reviews, 60(6), 638-656.

[12] Bhatt V, Rathore RP and Tanwar YS. (2014). Self micro emulsifying drug delivery system (SMEDDS): A review. Advance Research in Pharmaceuticals and Biologicals, 4(2), 664-669.

[13] Pathak CV, Gujarathi NA, Rane BR and Pawar SP. (2013). A review on self-micro emulsifying drug delivery system. Pharma science monitor-An international Journal of Pharmaceutical Sciences, 4(1), 3628-3648.

[14] Pattewar S, Kasture S, Pande V and Sharma S. (2016). Self-micro emulsifying drug delivery system: a lipid based drug delivery system, International Journal of Pharmaceutical Sciences and Research, 7(2), 443-452.

[15] Thimmaraju MK, Ramagiri V, Bheemanapally K, Bojja S, Kola V, Nerella R and Botlagunta M. (2013). Preparation and characterization of rosuvastatin calcium nanoemulsions. Latin American Journal of Pharmacy, 32, 1445-51.

[16] Lin SF, Chen YC, Ho HO, Huang WY, Sheu MT and Liu DZ. (2013). Development and characterization of dilutable self-microemulsifying premicroemulsion systems (SMEPMS) as templates for preparation of nanosized particulates, International Journal of Nanomedicine, 8, 3455-3466. 
[17] Atef E and Belmonte AA. (2008). Formulation and in-vitro and in-vivo characterization of a phenytoin selfemulsifying drug delivery system. European Journal of Pharmaceutical Sciences, 35, 257-263.

[18] Kaur M, Kaur G, Kaur H and Sharma S. Overview on Stability Studies, International Journal of Pharmaceutical, Chemical \& Biological Sciences, 3(4), 1231-1241.

[19] ICH Guideline. (2003). Stability testing guidelines: Stability testing of new drug substances and products. ICH Steering Committee, ICH Q1A (R2) (CPMP/ICH/2736/99).

\section{How to cite this article}

Mounika P, Vishnu P and Konde A. (2018). Development and characterization of self emulsifying drug delivery system of rosavastatin. GSC Biological and Pharmaceutical Sciences, 3(1), 01-10. 